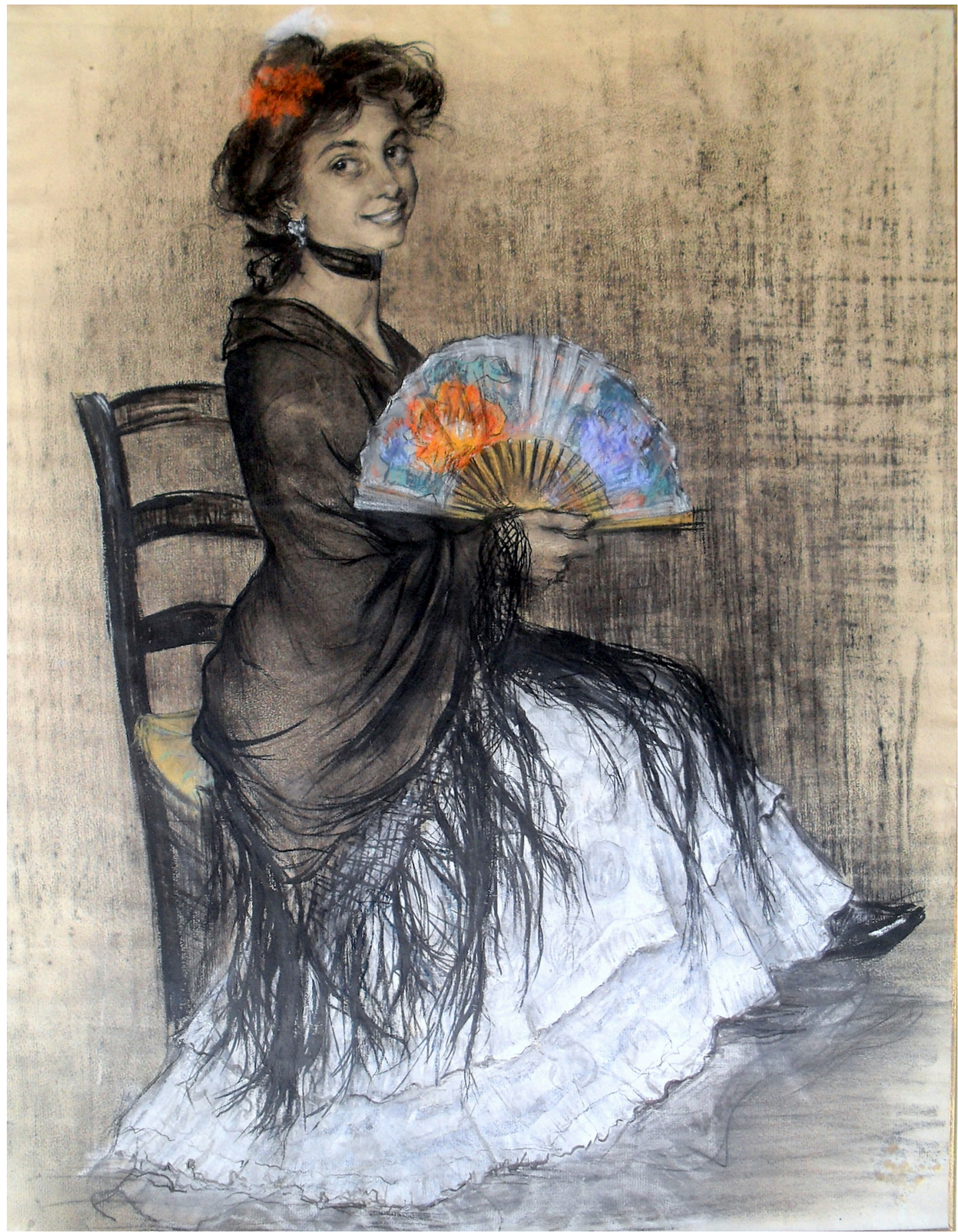

Fig. 1. Aurelia Navarro, Joven con mantón, h. 1905. Dibujo al carbón y pastel sobre papel, 59 x 46 cm. Colección Ignacio Navarro. 


\title{
"Una joven que vale mucho y que llegará a ser una pintora eminente": Aurelia Navarro en la escena artística española de comienzos del siglo $\mathrm{XX}$
}

"A Valuable Young Woman who will Become a Distinguished Painter": Aurelia Navarro in the Spanish Art Scene at the Beginning of the XX Century

\author{
Magdalena Illán Martín \\ Universidad de Sevilla, Espańa \\ magdaillan@us.es \\ https://orcid.org/0000-0002-4084-9223
}

\section{Resumen}

La pintora granadina Aurelia Navarro Moreno (1882-1968) desarrolló, durante las primeras décadas del siglo XX, una prolífica actividad creativa con la que concurrió a algunas de las exposiciones artísticas más relevantes del ámbito nacional y por la que obtuvo el beneplácito de la crítica, que destacó su "atrevimiento" y "valentía” en el tratamiento de asuntos tan polémicos, para una artista en estos momentos, como el desnudo. Este trabajo analiza la obra de Aurelia Navarro aportando nuevos datos sobre su evolución creativa y cuatro obras inéditas que

\begin{abstract}
The painter Aurelia Navarro Moreno (Granada, 1882-Córdoba, 1968) built a prolific creative career during the first decades of the 20th century. She participated in important art exhibitions and obtained the approval of critics who highlighted her "boldness" and "courage" when dealing with controversial topics of the time, such as nudes. This article analyzes the work of Aurelia Navarro and provides new data surrounding her creative evolution as well as four unpublished works. Keywords: women artists; gender studies; Spain; Andalusia; 20th Century; Aurelia Navarro.
\end{abstract}


se incorporan al catálogo de su producción.

Palabras clave: mujeres artistas; estudios de género; España; Andalucía; siglo XX; Aurelia Navarro.

Introducción

Aurelia Navarro Moreno (Granada, 1882-Córdoba, 1968) representa plenamente a las mujeres artistas —muchas de ellas aún escasamente conocidas en la actualidad—, que desarrollaron su talento creativo y ocuparon un lugar propio en la escena cultural española de finales del siglo XIX y comienzos del siglo XX. Su trayectoria artística fue tan breve como intensa, alcanzando su plenitud con apenas 25 años para, posteriormente, abandonar la que hubiera sido una prometedora carrera como pintora. Después, la historiografía artística ensombreció su figura hasta hacerla desaparecer, y hubo que esperar a estudios recientes para que fuera rescatada del olvido histórico y fuesen valoradas de forma justa sus aportaciones al arte español de las primeras décadas del siglo. ${ }^{1}$

Este artículo analiza la personalidad creativa de Aurelia Navarro a partir de información inédita procedente de la crítica artística del momento, la cual permitirá situar a la pintora en su contexto histórico - un contexto claramente hostil a la presencia de mujeres artistas en la escena cultural-y conocer la recepción de sus aportaciones por parte de los críticos de arte y de la sociedad en general. Asimismo, este artículo aporta el conocimiento de nuevas obras de Aurelia Navarro, que contribuirán a completar el aún inconcluso catálogo de su producción. ${ }^{2}$

\section{Mujeres artistas en España en las primeras décadas del siglo XX}

Ser mujer y artista — como señala Ana Aranda Bernal — ${ }^{3}$ en las primeras décadas del siglo XX en España no era fácil; tampoco lo era en el ámbito internacional, aunque en países como Francia, Reino Unido o Estados Unidos se había avanzado un poco más en la normalización de la presencia de las artistas en el espacio público. La sociedad española mantenía, en su amplia mayoría, un pensamiento conservador al respecto, e incluso las opiniones más liberales y opuestas a los postulados machistas heredados de la centuria decimonónica, continuaban defendiendo una percepción de las mujeres en la escena cultural basada en argumentos sexistas. Así, el periodista, fundador y director de la revista La Alhambra, Francisco de Paula Valladar, señalaba sobre Cándida López Venegas, participante en la exposición de caricaturas y tarjetas postales celebrada en 1908 en el Centro Artístico y Literario de Granada —a la que también concurrió Aurelia Navarro-, que era una "escritora distinguida, muy mujer de su casa y que además dibuja, pinta y borda como una artista;" continuaba, el periodista, analizando la presencia de las artistas en la exposición, utilizando una serie de argumentos en los que muestra su desagrado ante las mujeres que, según su parecer, pretenden inmiscuirse

1. Sobre Aurelia Navarro cfr. Mercedes Valverde y Francisco Zueras, Un siglo de pintura cordobesa, 1791-1891 (Córdoba: Diputación Provincial de Córdoba, 1984), 21-26; Estrella de Diego, La mujer y la pintura del XIX español (Cuatrocientas olvidadas y algunas más) (Madrid: Ed. Cátedra, 1987), 184, 197, 277; Juan Rodríguez Titos, Mujeres de Granada (Granada: Diputación Provincial de Granada, 1998), 95; Magdalena Illán Martín, "Aurelia Navarro," en Pintoras en España (1859-1926). De María Luisa de la Riva a Maruja Mallo, eds. Magdalena Illán Martín y Concha Lomba Serrano (Zaragoza: Prensas de la Universidad de Zaragoza, 2014), 158; Juan Manuel Segura Bueno, Granada artística en Casa Ajsaris (Granada: Asociación Granada artística, 2017), 228; Concha Lomba Serrano, Bajo el eclipse. Pintoras en España (1880-1939) (Madrid: CSIC, 2019), 57, 63.

2. Quiero expresar mi más sincero agradecimiento a D. Ignacio Navarro, familiar de Aurelia Navarro, por su valiosa dedicación a la recuperación y valoración de la figura de la artista, y por la ayuda facilitada para la elaboración de esta investigación, sin cuya colaboración no se hubiera podido llevar a cabo.

3. Ana Aranda Bernal, "Ser mujer y artista en la España de la Edad Moderna," en Roldana, coord. Antonio Torrejón y José Luis Romero (Sevilla: Consejería de Cultura, Junta de Andalucía, 2007), 33-51. 
en ámbitos que considera masculinos y ante aquellas que, en el campo artístico, no ejecutaran obras con los rasgos supuestamente femeninos. ${ }^{4}$ Además de la habitual valoración tendenciosa de su actividad creativa, las artistas tuvieron que superar y enfrentarse a la falta de seriedad — falta de responsabilidad profesional— por parte de los críticos en relación a los juicios que emitían sobre sus obras, en los que predominaba una rancia galantería, bajo la cual subyacía el menosprecio absoluto a sus producciones únicamente por el mero hecho de haber sido ejecutadas por mujeres: "Confieso ingenuamente que no sé ver las obras femeninas ni mucho menos criticarlas; todo cuanto hace esa bella mitad de nuestro linaje, me parece de perlas."”

No obstante, se advierte que en algunos sectores culturales esos postulados fueron dando paso a posturas más progresistas y próximas al "feminismo moderado" instalado en parte de la sociedad española. Así, en la revista cultural Álbum del Salón se rechazaron las actitudes de los "severos moralistas" que confinaban a la mujer a "no ser más que hija, esposa y madre" y se renegaba del estereotipo de "mujer recatada, modesta y virtuosa en la oscuridad;" pero, al mismo tiempo, la misma publicación recluía a las mujeres en el ámbito de las emociones - "la constituimos depositaria de la felicidad ruidosa, de las locas carcajadas" — y la expulsaba de cualquier actividad intelectual y científica. ${ }^{6}$

Con una mentalidad más liberal trata El Pais a las artistas participantes en la Exposición Nacional de Bellas Artes de 1908 —entre las cuales se encontraba Aurelia Navarro—; ello, a pesar de que el título del artículo sea "Exposición de Bellas Artes. Elogio del bello sexo" y de que se refiera a las expositoras con los habituales apelativos de "bellas y gentiles" y "legión de damas y señoritas que contribuyen al encanto y brillantez de la Exposición." Pese a lo expuesto, el periodista se refiere al "feminismo en el arte" como una realidad que avanza en las sociedades en pos de la igualdad de mujeres y hombres en la escena cultural y cuya trascendencia afectará al futuro de las artes; más aún, el autor critica acremente el lugar poco digno que ha sido adjudicado en la exposición a las obras presentadas por las artistas y que impide que puedan ser contempladas y valoradas justamente. ${ }^{8}$

Finalmente, es necesario señalar un ejemplo de los testimonios que en la prensa del momento abogan sin ambages por la presencia de las artistas en las exposiciones y celebra la valentía de aquellas mujeres que se atreven a enfrentarse a los estereotipos tradicionales: "dejamos para el final la nota más interesante de la Exposición, la nota femenina... Varias señoritas artistas, rompiendo valientemente con la rancia preocupación que aleja a la mujer de todo lo que sea manifestación de la vida intelectual, vienen estampando su firma al pie de

4. Francisco de Paula Valladar, "Exposición del Centro artístico y literario. Expo caricaturas y tarjetas postales," La Alhambra, 15 de julio de $1908,20:$ "No me agrada la mujer 'doctora', la que antes de saludar ha hecho entender á todo el mundo que solo por un descuido de la naturaleza no pertenece por el sexo á la categoría de los super-hombres; en cambio me agrada mucho que la mujer sienta el arte y la poesía, que escriba y pinte o haga estatuas, pero que las obras revelen que una mujer las pensó y las ejecutó."

5. Aureliano del Castillo, "La exposición del Centro," El defensor de Granada, 1 de octubre de 1908, 1. Sobre el uso, por parte de los críticos, del tono galante, cfr. Isabel Rodrigo Villena, "La galantería: una forma de sexismo en la crítica del arte femenino en España (1900-1936)," Asparkía, no. 31 (2017): 147-66.

6. "Nosotros le asignamos otra obligación igualmente digna de respeto: la constituimos depositaria de la felicidad ruidosa, de las locas carcajadas, de todos los goces de la vida. La mujer recatada, modesta y virtuosa en la obscuridad solo cumple a medias su tarea... Nada más espantoso que el egoísmo y el positivismo en el ser femenino, que ya comienza a ser sospechoso de insensibilidad por algunos hombres de ciencia que así explican la verdadera y profunda causa de su reserva," Carlos Baires, "Deberes de la mujer," Álbum del Salón, 1904, 15.

7. "Exposición de Bellas Artes. Elogio del bello sexo," El País, 8 de mayo de 1908, 1.

8. "El feminismo en el Arte es hoy día un hecho real, digno de la atención de la crítica; es un fenómeno que no puede sustraerse a nuestra consideración por lo que representa para el futuro posible de la pictórica y de las artes decorativas, y los instantes que a su estudio consagremos no serán minutos perdidos... Y al hablar de la representación femenina en la actual Exposición de Bellas Artes hemos de reconocer un acierto feliz en el Jurado de la Sección de Pintura; un acierto apenas esbozado, constreñido acaso por escrúpulos pueriles y de ninguna monta... y hay que censurar la torpeza o intención con que se condujo al hacer las instalaciones de algunos lienzos en el Salón central del pabellón. Y este loable acierto fue el agrupar en una sala las obras de varias expositoras, siendo lamentable que al decidirse por tan conveniente novedad no eligiese una cualquiera de las seis salas mayores de que consta el edificio, cuyas luces y fondos muy bien acondicionados ... hubiesen permitido lucir las bellas cualidades de las obras," "Exposición de Bellas Artes. Elogio del bello sexo." 
los trabajos." El anónimo periodista menciona, entre esas mujeres, a Aurelia Navarro, "cuyo nombre artístico se ha consagrado en la última Exposición bienal de Madrid" y de quien valora su talento "magistral."

\section{Aurelia Navarro Moreno: "gentil artista, gloria de nuestra tierra"/10} Nacida en Granada, las primeras noticias que la prensa recoge sobre Aurelia Navarro datan del año 1898, cuando contaba 16 años de edad. Aunque dichas noticias no aportan información sobre su formación o trayectoria artística, sin embargo, son reveladoras del entorno familiar en el que vivió su infancia y adolescencia, que sería determinante para su ulterior desarrollo como artista.

Hija del "ilustrado doctor en Medicina" ${ }^{11}$ granadino José Navarro y de Resurrección Moreno, la infancia de Aurelia transcurrió en el seno de una familia perteneciente a la burguesía ilustrada y con inquietudes culturales, literarias y artísticas. De hecho, la prensa destacó en su padre la "brillantez de sus recursos literarios"12 y la habilidad como pianista de su tío Emilio Moreno y de la hija de este, Amalia Moreno, "discípula aventajadísima del pianista Emilio Vidal (...) que ejecuta con la habilidad y sentimiento de una verdadera artista." ${ }^{3}$

No sorprende, por lo tanto, que Aurelia Navarro recibiera una educación orientada al desarrollo de sus aptitudes creativas a través del aprendizaje de dibujo y pintura, como era habitual entre las jóvenes de la burguesía española desde el siglo XIX, aunque, es preciso señalarlo, dicha educación no tenía el objetivo de promover en ellas una vocación artística —y menos aún un interés profesional—, sino como parte de una formación dirigida a favorecer sus cualidades en el hogar, como esposas y anfitrionas. En este mismo sentido se manifestaba el pintor, escritor y profesor de numerosas estudiantes de arte en estos momentos José Parada Santín al escribir que "las artes, y especialmente la pintura, pueden ocupar con provecho la imaginación y los ocios de las mujeres (...) en manera alguna puede perjudicar a las condiciones que pudiéramos llamar domésticas de la mujer (...) Contribuye a perfeccionar el sentido estético en la mujer." ${ }^{14}$

La adolescente Aurelia Navarro aprendió los rudimentos básicos del dibujo y la pintura en el taller privado del artista granadino José Larrocha (1850-1933), maestro de una amplia generación de pintores, entre los que han de citarse José María López Mezquita (1883-1954) y José María Rodríguez Acosta (1878-1941), con quienes la artista pudo compartir sus inquietudes creativas. José Larrocha hubo de transmitir a Aurelia Navarro un profundo interés por las representaciones del paisaje granadino, tanto de los espacios urbanos y los entornos próximos a la Alhambra y Generalife, como de los espacios rurales y naturales, que la artista continuó recreando durante toda su trayectoria. Asimismo, hubo de realizar en el estudio de este maestro sus primeras obras de temática costumbrista, enmarcadas en los cármenes y jardines de Granada, que no dejará de estar presente en su producción ulterior.

Cuando Aurelia Navarro contaba 18 años de edad, inició una nueva etapa en su formación asistiendo al taller del laureado pintor cordobés Tomás Muñoz Lucena (1860-1943) quien, tras ser nombrado profesor de

\footnotetext{
9. "Exposición del Centro Artístico y Literario. Exposición de caricaturas y tarjetas postales," La Publicidad, 18 de junio de $1908,4$.

10. José María Caparrós, "Exposición de Otoño," Noticiero granadino, 29 de septiembre de 1908, 1.

11. El Defensor de Granada, 1 de marzo de 1904, 2

12. "En la provincia," El Defensor de Granada, 15 de marzo de 1898,1

13. "En la provincia," El Defensor de Granada, 5 de febrero de 1898, 1.

14. José Parada y Santín, Las pintoras españolas. Boceto histórico-biográfico y artístico (Madrid: Imprenta del Asilo de Huérfanos del S. C. de Jesús, 1902$), 78$.
} 
dibujo en el Instituto de Córdoba en 1894, pasó a desempeñar, en el año 1900, el cargo de catedrático de dibujo en el Instituto General y Técnico Padre Suárez de Granada. Con Muñoz Lucena, formado en la Escuela de Bellas Artes de San Fernando de Madrid con Federico de Madrazo, pensionado en la Academia de Espańa en Roma y premiado en diferentes ediciones de las exposiciones nacionales de bellas artes, ${ }^{15}$ adquirió Aurelia Navarro un mayor rigor en el sentido del dibujo y de la composición. Igualmente, con Muñoz Lucena, que había estado en París y había incorporado a su obra de temática costumbrista influencias impresionistas, Aurelia Navarro desarrolló en su producción un sentido de la luz y del color más experimental y una factura más ágil, recursos que incorporó a sus pinturas de paisajes y asuntos cotidianos. Son numerosas las obras que se conservan ejecutadas por el maestro y la discípula, que revelan que ambos artistas compartieron inquietudes plásticas, motivos de inspiración, asuntos y modelos, aunque cada artista las interpretó a partir de sensibilidades propias y diferenciadas.

Con los albores del siglo XX Aurelia Navarro comenzó su carrera artística en la escena pública, superando la controvertida frontera de los espacios privados de los estudios de los maestros, o del espacio doméstico, y adentrándose en espacios públicos y competitivos, en los que la presencia de las mujeres, lejos de estar normalizada, era considerada una amenaza al orden tradicional establecido. Así, fue pensionada por la Diputación Provincial de Granada ${ }^{16}$ y comenzó a exhibir su obra en las principales exposiciones del ámbito nacional, como las exposiciones nacionales de bellas artes, y del escenario cultural granadino, como el Centro Artístico, Literario y Científico.

También participó Aurelia Navarro en iniciativas que se desarrollaron en España en la primera década del siglo con objeto de renovar el panorama artístico existente y fortalecer la profesionalización de los artistas, como la Asociación de Pintores y Escultores de España. Fundada en el año 1910, dicha asociación contaba con un instrumento de difusión que era la Gaceta de la Asociación de Pintores y Escultores -posteriormente denominada Gaceta de Bellas Artes-, en cuyo primer número, editado en julio del referido año, se mencionaban sus objetivos: " $1{ }^{\circ}$, la unión de todos los artistas profesionales de la Pintura, Escultura, Artes derivadas de los mismos y Profesores de Enseńanza de Arte.... 2º La defensa por todos los medios legales de sus intereses materiales y artísticos, tales como propiedad artística, derechos de reproducción de obras, opción a puestos públicos tanto en la enseñanza como en museos y demás establecimientos oficiales, etc. etc... 3o, El fomento y mejora de todas las manifestaciones del Arte, como celebración de Exposiciones en Espańa y en el Extranjero, Intervención en las convocadas por el Estado, las provincias o ciudades, así como en los certámenes y concursos, etc." ${ }^{17}$ En ese primer número de la revista consta Aurelia Moreno entre los "Señores Socios de Número," con el número 80, formando parte, por lo tanto, del primer grupo de artistas vinculados a la asociación, cuyo número total ascendía a 267 y de los cuales, solo 11 eran mujeres. ${ }^{18}$

La referida participación de Aurelia Navarro en la Asociación de Pintores y Escultores de España pone de relieve, una vez más, el compromiso contraído por parte de la artista con su actividad creativa y con su futuro

\footnotetext{
15. Obtuvo medalla de segunda clase en 1887 con la pintura El cadáver de Álvarez de Castro (300 x $475 \mathrm{~cm})$, perteneciente al Museo del Prado, y primera medalla en el año 1901 por Plegaria en las ermitas de Córdoba (1900). Sobre Muñoz Lucena, Tomás Muñoz Lucena. Un cordobés en Granada (Granada: Asociación Granada artística, 2018).

16. Museo Virtual Diputación de Granada, "Aurelia Navarro Moreno," consultado el 30 de enero de 2019,

http://museovirtual.dipgra.es/es/artista/aurelia-navarro-moreno

17. "La Asociación de Pintores y Escultores," Gaceta de la Asociación de Pintores y Escultores, no. 1, julio de 1910, 1.

18. "Lista por orden alfabético. Señores socios de número," Gaceta de la Asociación de Pintores y Escultores, no. 1, julio de 1910, 11. Las artistas que, junto a Aurelia Navarro, configuraron el núcleo inicial de la Asociación fueron las siguientes: entre los "Señores Socios Fundadores," Carmen Alcoverro, Luisa Botet y Mundi, Par Erguía, Pilar Montaner y Marcelina Poncela de Jardiel; entre los "Señores Socios de Número" se encuentran María del Adalid, Carmen Baroja de Nessi, Fernanda Francés de Arribas, Pilar Huguet Crexells y María López.
} 
profesional como pintora. ${ }^{19}$ Un compromiso que hubo de verse, sin duda alguna, alentado por los galardones obtenidos en los certámenes artísticos, así como por la popularidad que alcanzó en la prensa granadina, que no solo recogía información de sus logros artísticos, sino que también se interesaba por su vida personal. ${ }^{20}$

\section{Aurelia Navarro ante la crítica artística de comienzos del siglo XX}

La recepción que la obra de Aurelia Navarro tuvo por parte de la crítica de arte fue, de forma generalizada y casi unánime, muy positiva; y ello, conviene no dejar de tenerlo presente, a pesar del sesgo marcadamente sexista que imperaba en las mentalidades de los críticos del momento y que, en ocasiones, obligaba a las artistas a firmar las obras con sus iniciales, evitando cualquier indicio que pudiera revelar la autoría de una mujer. ${ }^{21}$

Las primeras valoraciones emitidas por la crítica sobre la obra de Aurelia Navarro se publicaron en el año 1904, cuando la artista presentó en la Exposición Nacional de Bellas Artes la pintura Sueño tranquilo. ${ }^{22}$ Bien valorada por los críticos, el "sugestivo cuadro representa una nińa que se ha quedado dormida sentada en una mecedora, y tan bien duerme, que parece se le va a oír la respiración, y hay temor de despertarla." ${ }^{23}$ Las positivas críticas recibidas, ${ }^{24}$ así como la mención honorífica obtenida en la exposición — con un jurado presidido por el insigne Joaquín Sorolla- hubieron, sin duda, de estimular a la joven artista de 22 ańos y que participaba por primera vez en la muestra, a continuar su trayectoria.

La pintura Sueño tranquilo revela, en gran medida, las inquietudes creativas de Aurelia Navarro y su deseo por desarrollar soluciones arriesgadas desde el punto de vista compositivo y plástico. Así, la visión de la niña a partir de un punto de vista en picado y la composición marcadamente diagonal y cortada abruptamente en sus flancos, ofrece una imagen espontánea e íntima de la escena. Al mismo tiempo, la artista conjuga elementos tradicionales en el tratamiento de la anatomía de la figura y en el uso de una gama cromática de tonos pardos armonizados, con un tratamiento bosquejado de empastes grumosos en la descripción de la blusa blanca y de las flores violetas dispuestas sobre el pecho.

Dos años más tarde, en la siguiente edición de la Exposición Nacional de Bellas Artes celebrada en 1906, Aurelia Navarro concurrió nuevamente con una pintura en la que volvió a manifestar, aún con mayor énfasis, su decidida voluntad de alcanzar reconocimientos en la escena artística. La pintura, presentada con el título Retrato de señorita, ${ }^{25}$ es, muy probablemente, un autorretrato de la artista; en ella se describe a una figura femenina, situada de perfil y de algo menos de medio cuerpo, que sostiene un pincel en su mano derecha y concentra su mirada y su atención en un punto situado fuera de la composición. Como en Sueño tranquilo, la artista ha sabido

\footnotetext{
19. Sin embargo, poco tiempo después, en septiembre de 1910, recoge la publicación la última referencia a Aurelia Navarro, en la que se deja constancia del pago de seis pesetas correspondientes a tres cuotas de socia, señalándose que han sido recibidas sobre monedera "sin fijar fecha ni punto de residencia, ni leerse este en los estampillados del Correo," Gaceta de la Asociación de Pintores y Escultores, no. 3, septiembre de 1910, 16.

20. Así, El Defensor de Granada, 9 de septiembre de 1906, 1, señala que "la bella y laureada artista Srta. Aurelia Navarro" se encuentra enferma, aunque sin gravedad.

21. Magdalena Illán y Custodio Velasco Mesa, "'Un verdadero pintor': María Luisa Puiggener en la escena artística sevillana de comienzos del siglo XX," Laboratorio de Arte, no. 30 (2018): 401-18.

22. La obra, óleo sobre lienzo $(66 \times 41 \mathrm{~cm})$ está firmada por la artista y fue reproducida en Valverde y Zueras, Un siglo de pintura cordobesa, 116.

23. El Álbum Ibero-Americano, no. 23, 22 de junio de 1904, 5.

24. Son numerosas las felicitaciones publicadas en los medios granadinos a la artista, haciendo hincapié en su "merecidísimo triunfo" y trasladando la enhorabuena al "reputado médico granadino D. José Navarro," Noticiero granadino, 31 de mayo de 1904, 2; El Defensor de Granada, 1 de junio de $1904,1$.

25. Óleo sobre lienzo $(66 \times 43 \mathrm{~cm})$, la obra está firmada "Aurelia Navarro." La pintura fue reproducida en Valverde y Zueras, Un siglo de pintura cordobesa, 119
} 
compaginar un riguroso sentido del dibujo y un mesurado uso del color en el rostro de la figura con un expresivo y ágil tratamiento de la pincelada en la descripción de las zonas periféricas del lienzo, como la mano y la indumentaria, resuelta con pinceladas largas, densas y matéricas. Aunque esta obra no obtuvo tanta atención como la anteriormente mencionada por parte de la crítica, ${ }^{26}$ no obstante, la artista logró una medalla de tercera clase en la Exposición Nacional de Bellas Artes, lo que contribuyó a posicionarla en la escena nacional y a consolidar su figura en el espacio cultural granadino, ya que la prensa local se hizo eco, con orgullo, del galardón. ${ }^{27}$

Sin duda alguna, el momento en el que Aurelia Navarro alcanzó un mayor reconocimiento fue el año 1908 y, concretamente, a raíz de su participación en la Exposición Nacional de Bellas Artes, en la que presentó la pintura Desnudo de mujer. ${ }^{28}$ Se trataba de una apuesta arriesgada por parte de la artista, ya que la mentalidad de la sociedad española del momento y, formando parte de ella, la de los críticos coetáneos, continuaba considerando el tema del desnudo en el arte como un asunto eminentemente masculino y cuyo tratamiento por parte de las artistas no dejaba de tener un carácter polémico. ${ }^{29} \mathrm{Al}$ respecto, es necesario recordar que en las primeras décadas del siglo XX persistía el concepto decimonónico de preservar el decoro de las mujeres alejándolas de la visión de cuerpos desnudos, masculinos o femeninos, por lo que las enseñanzas artísticas para las mujeres no contemplaban asignaturas que pudieran promover el conocimiento de la anatomía del natural, como bien se quejaba de ello el ya referido José Parada y Santín. ${ }^{30}$ Huelga insistir, por tanto, en que el hecho de que una artista concurriera a las exposiciones con una pintura que representara un desnudo no iba a ser recibido con complacencia por parte de la crítica.

Sin embargo, Desnudo de mujer de Aurelia Navarro, contra todo pronóstico y salvo contadas excepciones, obtuvo no solo el beneplácito de la crítica, sino la legitimación del sistema para que una artista pudiera ejecutar dicho tema: "Dejemos en el olvido el arte moralista: no es tal arte. Ahí está Desnudo de mujer, de la señorita Aurelia Navarro, invitándonos a reconciliarnos con la vida en lo que de más adorable tiene, en la juventud, en la forma humana, vaso que contiene la esencia de la divinidad."31 También Valladar justificó el tratamiento del desnudo por parte de la artista: "de tal modo se ha impuesto desde el primer día en la opinión, que nadie ha pensado en criticar que a una mujer, bella y joven, educada con todas las delicadezas propias de una distinguida seńorita, hija de un reputado médico y de una seńora de reconocida cultura, se le haya ocurrido estudiar el modelo vivo, el desnudo, base firme del dibujo de figura." ${ }^{32} \mathrm{Y}$ no solo no fue rechazada la pintura, sino que, en una exposición en la que una de sus primeras medallas recayó en otro desnudo, La musa gitana de Julio Romero de Torres, la joven Aurelia Navarro de 26 años fue incluida entre los artistas que garantizaban en dicho tema una "briosa y afortunada representación,"33 como el mencionado Romero de Torres, Santamaría e Ibaseta, siendo calificada su obra como un

\footnotetext{
26. Son escasas las referencias localizadas y con apreciaciones discretas, con los habituales argumentos para las obras realizadas por artistas: "doña Ana de Gutiérrez, de Granada, y la señorita Navarro, paisana suya, presentan unos cuadros muy aceptables y delicados." Santiago Casanova, "Los artistas andaluces en la Exposición de Bellas Artes," La Alhambra, 30 de mayo de 1906, 17.

27. "Tercera medalla por un Retrato," Noticiero granadino, 26 de mayo de 1906, 1. Cuatro meses después, una pintura de Aurelia Navarro -junto a otras obras de los artistas López Mezquita, Latorre, Santacruz, Vergara y Gómez Gálvez- fue ofrecida como premio en la exposición de Labores de la mujer celebrada en Granada, cfr. "La exposición de labores," El Defensor de Granada, 8 de septiembre de 1906, 1.

28. La pintura, óleo sobre lienzo $(93 \times 160 \mathrm{~cm})$ se conserva en la colección de la Excma. Diputación Provincial de Granada.

29. Sobre el tratamiento del desnudo por parte de las artistas españolas a comienzos del siglo XX, cfr. Lomba Serrano, Bajo el eclipse, $169-75$.

30. "Hoy en día está atrasadísimo el concepto de la enseñanza artística de la mujer en España... Yo he tenido el honor, con un artículo publicado en 'El Liberal', de abrir el palenque de las oposiciones a Roma a las mujeres. Gracias a esto pudo tomar parte en los ejercicios Inocencia Arangoa... Tampoco se les permite la matrícula en varias clases, pretextando que en ellas hay modelo desnudo, y en cambio se han concedido a mujeres títulos de Doctora en Medicina," cfr. Parada y Santín, Las pintoras españolas, 79

31. Rafael Balsa de la Vega, "Exposición General de Bellas Artes II. La pintura," La llustración española y americana, 15 de mayo de $1908,11$.

32. Francisco de Paula Valladar, "Los pintores granadinos en la Exposición Nacional II," El Defensor de Granada, 29 de mayo de $1908,1$.

33. La Alhambra, 15 de mayo de 1908, 14. "Es uno de los desnudos pintados con más solidez entre los presentados," $A B C, 11$ de junio de $1908,13$.
} 
"magnífico y valiente desnudo." ${ }^{44}$ Incluso las opiniones más conservadoras valoraron positivamente la pintura, pasando por alto que la autora se había introducido en uno de los bastiones del pensamiento artístico sexista, como era el tratamiento del desnudo. ${ }^{35}$

Al margen de la controversia que podía suscitar el que la autora de Desnudo de mujer fuese una pintora - $-\mathrm{y}$, más aún, que fuese un autorretrato-, la obra hubo de satisfacer plenamente los requisitos del jurado de la exposición, tanto por el tratamiento compositivo, el dibujo y el color compaginando el tratamiento suavemente nacarado de la anatomía de la joven con la agilidad empastada de las flores apenas abocetadas-, como por el homenaje a la Venus del espejo de Velázquez, en un momento de auge nacionalista en el arte espańol, por lo que fue premiada con una tercera medalla. Esa medalla obtenida por Aurelia Navarro —única mujer galardonada con medalla en dicha exposición junto a María Gutiérrez Cueto, posteriormente, María Blanchardno satisfizo a los numerosos críticos, que manifestaron su decepción y reclamaron para la artista un mayor galardón. ${ }^{36}$

La pintura fue propuesta para ser adquirida por la Diputación de Granada,

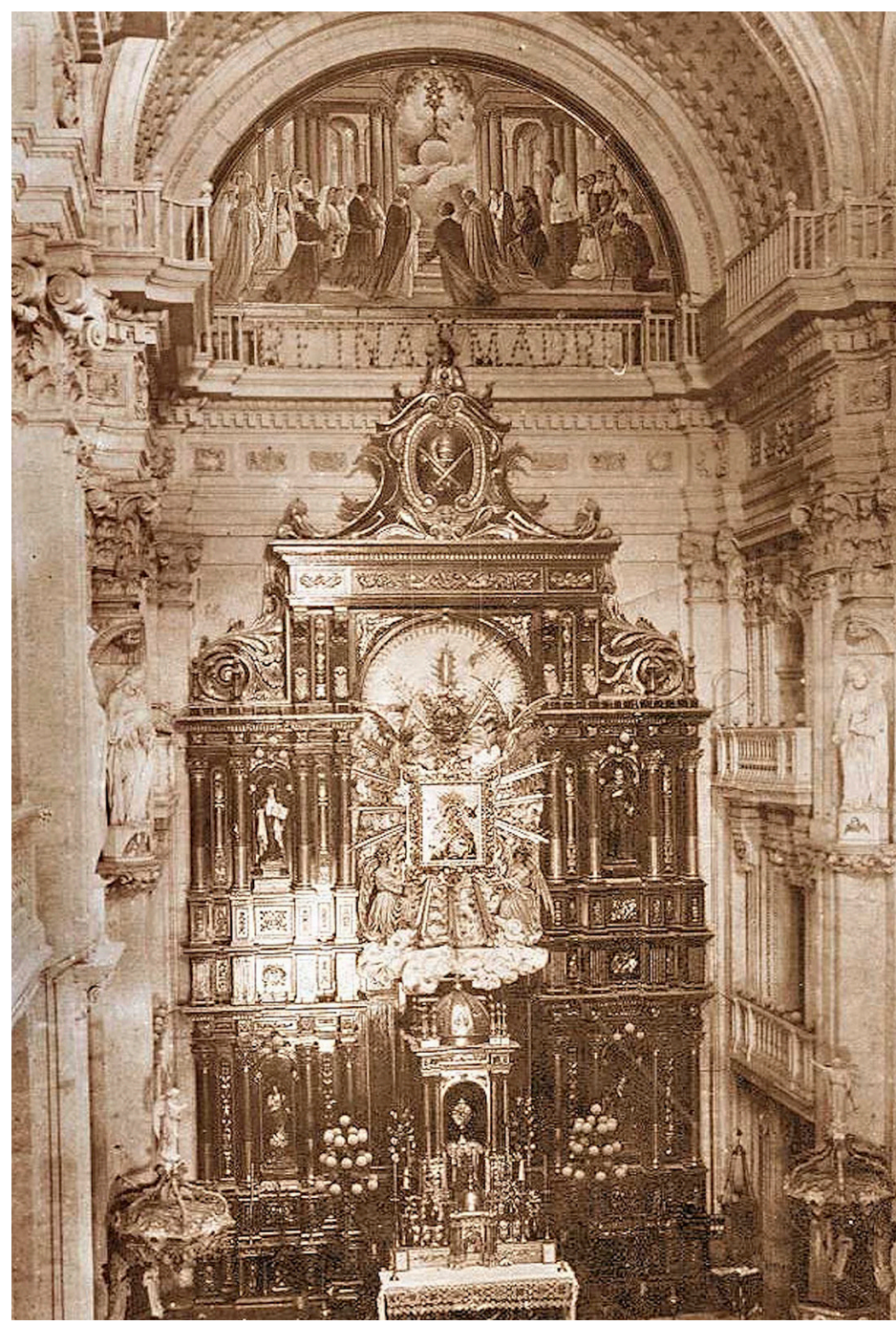

Fig. 2. Aurelia Navarro, Santísimo Sacramento, 1908. Santuario de Nuestra Señora del Perpetuo Socorro, Redentoristas de Granada. Fotografía disponible en https://www.santuarioperpetuosocorro.com/historia-archicofradia-nuestra-senora-del-perpetuo-socorro-granada argumentándose, además de su valía artística, el hecho de que dicha adquisición estimularía a la artista para que continuara "con aprovechamiento el arte que cultiva con tanta brillantez." ${ }^{37}$ Y conforme a ello, la obra fue adquirida en precio de 2000 pesetas, para ser colocada en el salón de sesiones de la corporación granadina.

El éxito logrado por Aurelia Navarro en la Exposición Nacional de Bellas Artes contribuyó a difundir su obra a través de la prensa, reproduciéndose algunos de sus dibujos realizados a plumilla en algunos medios,

34. Francisco de Paula Valladar, "Los pintores granadinos en la Exposición Nacional," El Defensor de Granada, 24 de mayo de $1908,1$.

35. "Sin comulgar en lo ridículo del tan traído y llevado feminismo, muéstrase la joven y bella artista cultivadora ferviente del modelo vivo y su Desnudo de mujer es, sencillamente, una obra maestra que ha llamado la atención de cuantos han visitado aquellos salones. Granada puede estar satisfecha de contar entre sus verdaderos artistas una joven que vale mucho y que llegará á ser una pintora eminente," Valladar, Francisco de Paula, "Los pintores granadinos," La Alhambra, 31 de mayo de $1908,20$.

36. "La notable artista que acaba de obtener en Madrid una Tercera medalla —merecía más en conciencia—,"Valladar, 31 de mayo de $1908,20$.

37. "Una artista de mérito," El Defensor de Granada, 14 de mayo de 1908, 1; el artículo describe la asamblea de la Diputación de Granada, en la que Agustín Rodríguez Aguilera lleva a cabo la propuesta de la adquisición, que fue aprobada por unanimidad. La Publicidad, 14 de mayo de 1908, 2, señala que también se argumentó "su situación de carecer de bienes de fortuna para desarrollar sus facultades." 
como Desnudo — una representación de un frágil desnudo infantil arrodillado- y El almuerzo —en el que una joven alimenta a unos pavos-.$^{38}$ Además, los reconocimientos y la fama alcanzados por la artista en este ańo de 1908 le llevaron a desarrollar diferentes iniciativas creativas, como la pintura de gran formato que realizó para el santuario de Nuestra Señora del Perpetuo Socorro de Granada y que tuvo un buen recibimiento por parte de la sociedad granadina. ${ }^{39}$ La obra, titulada Santísimo Sacramento, fue ejecutada para presidir el baptisterio del templo ${ }^{40}$ (Fig. 2) y está protagonizada por el Santísimo Sacramento, dispuesto en una custodia que se sitúa sobre un orbe, rodeada por destellos dorados y ángeles en la zona superior y con una cohorte de santos en la inferior. En ella, Aurelia Navarro hubo de demostrar su elevada capacidad para el desarrollo de las perspectivas arquitectónicas que enmarcan la composición, así como para la ejecución de un numeroso grupo de figuras de santos, mayores del tamaño natural, que aparecen perfectamente integradas en el espacio.

También en junio de ese mismo año de 1908 participó Aurelia Navarro en la Exposición de caricaturas y tarjetas postales organizada por el Centro Artístico, Literario y Científico de Granada. Una muestra tipificada dentro del denominado "humorismo artístico" y que ofrecía una percepción del arte menos académica, más fresca e innovadora. El interés de la artista por la renovación de las artes le llevaría a participar en esta muestra, donde presentó, en la categoría de tarjetas postales, unas obras "magistralmente pintadas" protagonizadas por "cuatro figuras de mujer." ${ }^{11}$ Tres meses más tarde concurrió a la Exposición de Otoño organizada por la misma institución, en la que exhibió un Estudio de figura que fue muy bien valorado por la crítica, destacando especialmente el inteligente uso de la luz: "La señorita Navarro presenta una figura con motivo a difíciles estudios de luz y sombra. Con decir que la señorita Navarro ha salido triunfante en $\tan$ espinosa empresa, queda hecho el mejor elogio de la obra que exhibe. En dicho cuadro se notan pinceladas acertadísimas." ${ }^{42}$ Es reseñable que en dicha exposición la valoración de la obra presentada fue paralela a la valoración de la propia artista, siendo incluida entre los artistas que estaban "ungidos por el incienso de la gloria, Rodríguez Acosta, Bertuchi, Moreu, Larrocha, Latorre, Aurelia Navarro y algún otro.”³

A partir de 1910 la presencia de Aurelia Navarro en las exposiciones artísticas se redujo de forma drástica. Consta su participación en la exposición organizada por el Centro Artístico, Literario y Científico de Granada en junio de 1914, con una pintura titulada La oración, ${ }^{44}$ y dos años más tarde, en una muestra organizada por la misma institución, en la que presentó la pintura Éxtasis. ${ }^{45}$

38. Fueron reproducidos en La Alhambra, Granada, 15 de enero de 1908, 4 y en El Defensor de Granada, 29 de mayo de $1908,1$.

39. "Un cuadro hermoso," La Publicidad, 6 de octubre de 1908, 2.

40. Edificado en 1671 bajo la dirección de Melchor de Aguirre, el templo estuvo vinculado a la Congregación del Oratorio de San Felipe Neri; fue cerrado y abandonado en la desamortización de Mendizábal de 1836 y los filipenses fueron expulsados. A comienzos del siglo XX los Misioneros Redentoristas recuperaron la función pastoral misionera del templo, bajo el título de santuario de Nuestra Señora del Perpetuo Socorro. En la actualidad la pintura de Aurelia Navarro no se encuentra en el lugar para el que fue realizada.

41. Ambas referencias proceden de "Exposición del Centro Artístico y Literario," La Publicidad, 18 de junio de 1908, 4, que señala también la participación de otras tres artistas: Josefa Aznar, quien presentó "una colección de ramos de flores," valorada como "obra propia de un maestro;" Cándida López Venegas, quien exhibió "dos paisajes llenos de luz" y Rosario López Soler, que concurrió con "dos pasajes del Quijote, dignos del pincel de Moreno Carbonero, dos paisajes y una figura." Otras fuentes señalan la participación de María Mollet y María J. Amor, cfr. "Exposición del Centro Artístico y Literario," La Alhambra, 15 de julio de 1908, 20.

42. "Centro Artístico y Literario. Exposición de Otoño. Sala III," Gaceta del Sur, 6 de octubre de 1908, 1. Otras críticas se manifiesta en un sentido similar: "Muy bueno y de gran dificultad: una muchacha llevando encendida una capuchina, cuya luz oculta con la mano derecha," Aureliano del Castillo, "La exposición del Centro," El Defensor de Granada, 1 de octubre de 1908, 1; "Aurelia Navarro, la gentil artista, gloria de nuestra tierra, pródiga en mujeres de gracia y talento, expone una Figura de niña, cuyo rostro bañado de luz artificial es una prueba de obstáculos. Está colocada en el sitio de los privilegiados, con toda justicia," Caparrós, "Exposición de Otoño." Otras artistas que participaron en la muestra fueron: Carmen Alberá -Paisaje, carbón-, María Josefa Aznar -dos Paisajes granadinos- y Pilar Millet de Martos -Bodegón-; "La exposición del Centro," El Defensor de Granada, 27 de septiembre de $1908,1$.

43. José Martínez de Federico, "La exposición de Bellas Artes," La Publicidad, 30 de junio de 1908, 1.

44. "La exposición del Centro," El Defensor de Granada, 10 de junio de 1914, 2; cfr. también La Alhambra, 30 de junio de $1914,24$.

45. "Centro artístico," El Defensor de Granada, 1 de julio de 1916, 1; también se recoge la participación de Mary Degen, con cuatro pinturas: La Bilbainita, Desnudo, Estudio y Retrato. 


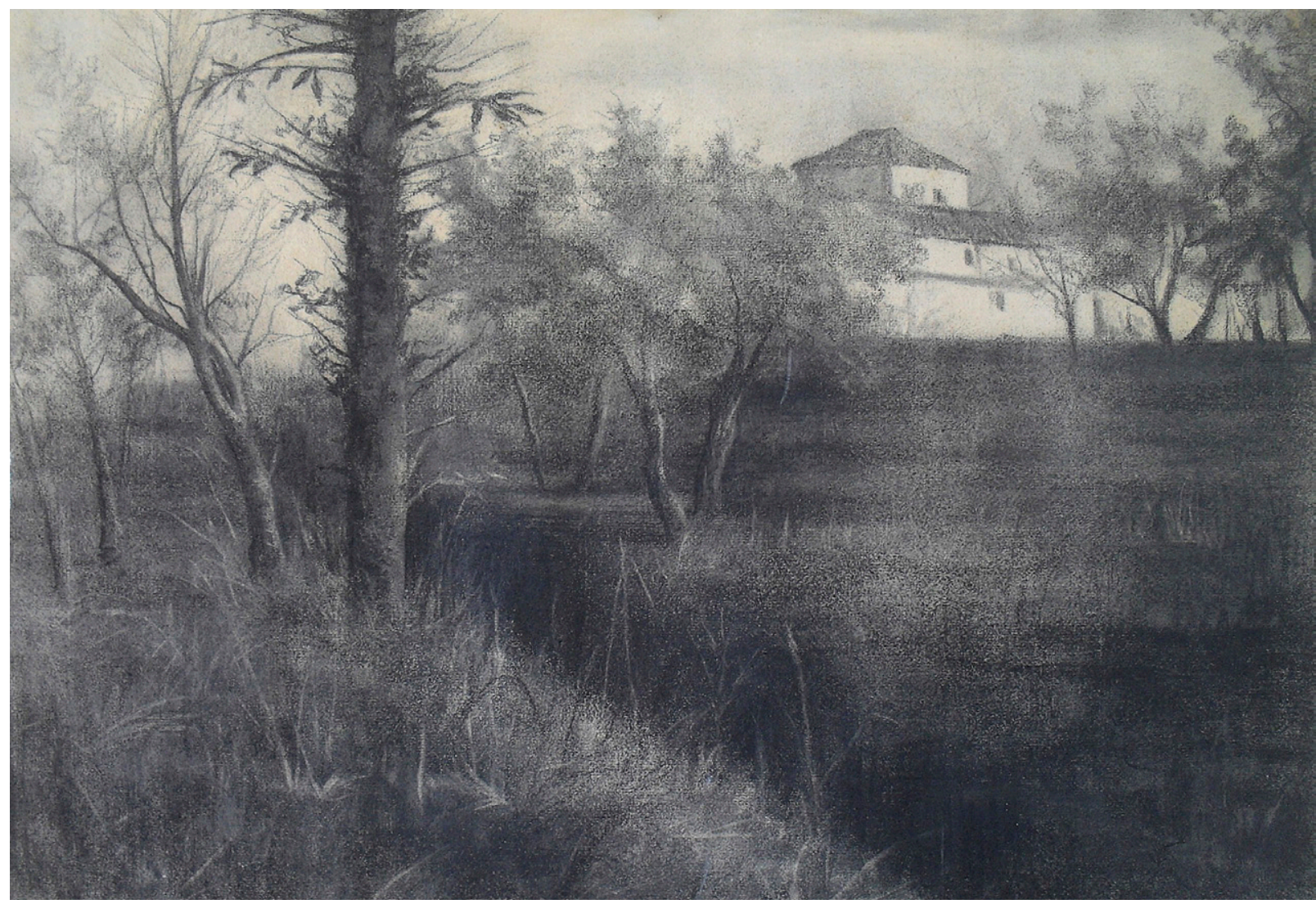

Fig. 3. Aurelia Navarro, Paisaje, h. 1900. Dibujo al carbón sobre papel, 40 × 57 cm. Colección Ignacio Navarro.

Finalmente, en el ańo 1923 la prometedora trayectoria artística de Aurelia Navarro se vio truncada al ingresar como monja en la orden religiosa de las Adoratrices Esclavas del Santísimo Sacramento. Desde dicho momento residió en el convento de la orden en Córdoba, que no abandonó más que para desplazarse al Vaticano en 1933 para realizar un retrato de la fundadora de la orden, la Madre Sacramento — santa María Micaela del Santísimo Sacramento (1809-1856)_, con motivo de su canonización en 1934. ${ }^{46}$ Falleció Aurelia Navarro el 9 de febrero de 1968.

\section{Aproximación a la producción artística de Aurelia Navarro}

La producción artística realizada por Aurelia Navarro muestra un variado perfil en cuanto a las temáticas representadas, predominando los paisajes y las escenas costumbristas, seguidas por el retrato y, en último lugar, las representaciones de flores, bodegón y desnudo, todas ellas ejecutadas al óleo, carbón, plumilla o pastel.

El género del paisaje atrajo especialmente a la artista, dedicándole una amplia parte de su producción en forma de óleos y de dibujos a plumilla y carbón. Como su primer maestro, José Larrocha, dos son los intereses fundamentales de Aurelia Navarro en relación a este asunto: los espacios de la Alhambra y Generalife y los alrededores de Granada, en algunos de los cuales incluye Sierra Nevada. En ambos casos, la artista 


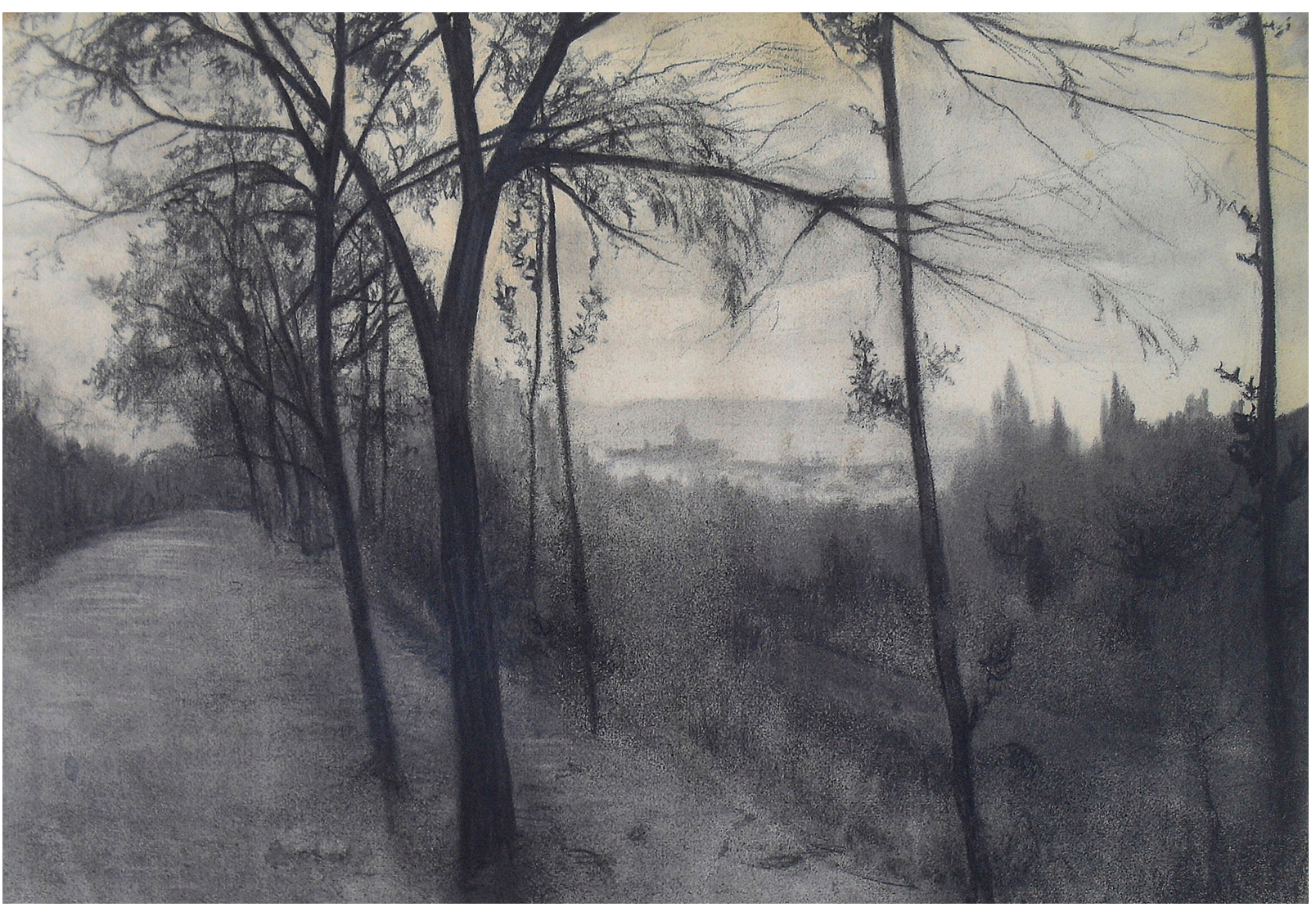

Fig. 4. Aurelia Navarro, Paisaje, h. 1900. Dibujo al carbón sobre papel, 40 × 57 cm. Colección Ignacio Navarro.

utiliza fórmulas similares, en las que recrea visiones fragmentarias del paisaje en composiciones que rehúyen las soluciones académicas y equilibradas, introduce encuadres cortados abruptamente que cercenan las copas de los árboles para conceder protagonismo a los troncos y sitúa las líneas del horizonte marcadamente elevadas. Los dos Paisajes ${ }^{47}$ (Figs. 3 y 4 ) de la colección Ignacio Navarro responden a dicho modelo y podrían situarse en la primera etapa de la artista, con una visible influencia de su maestro Larrocha. Se advierte en ellos que hay un sentido académico en la composición, trazando la profundidad espacial mediante diagonales, y un carácter realista en la ejecución de los volúmenes, aspectos que posteriormente darán paso a una mayor labor de síntesis y de geometrización de los elementos representados. Ambos paisajes demuestran el elevado nivel técnico alcanzado por Aurelia Navarro en su primera etapa formativa, con un riguroso sentido del dibujo que se mantendrá, aunque de forma menos evidente, a lo largo de su producción, y una exquisita sensibilidad en el tratamiento difuminado de las luces y las sombras que, en los años ulteriores, adquirirá un carácter más contrastado bajo la influencia del impresionismo y el luminismo.

Las escenas costumbristas que configuran la producción de Aurelia Navarro están protagonizadas, sobre todo, por mujeres, advirtiéndose un interés inicial por episodios de la vida cotidiana situados en espacios interiores y marcados por un espíritu dramático, en la línea del realismo académico de carácter social practicado por otros ar-

47. Ambas obras, dibujos al carbón sobre papel, miden $40 \times 57 \mathrm{~cm}$. Agradezco a D. Ignacio Navarro haberme dado a conocer las cuatro obras que se presentan en este trabajo y permitir su reproducción. 
tistas andaluces coetáneos, como Romero de Torres o María Luisa Puiggener. Las protagonistas son, especialmente, niñas de rostros graves, dispuestas en espacios oscuros descritos con una gama de tonos ocres y negros, que la artista también aplica a los retratos de esta época. En los primeros años de la nueva centuria, su paleta se aclara y la luz inunda las composiciones, que pasan a situarse en espacios abiertos; incorpora la artista una pintura à plein air, en la que la pincelada adquiere agilidad y matices en sus empastes, mientras el dibujo se vuelve suelto y esencial, otorgando movimiento y espontaneidad a las escenas. Las protagonistas de estas obras

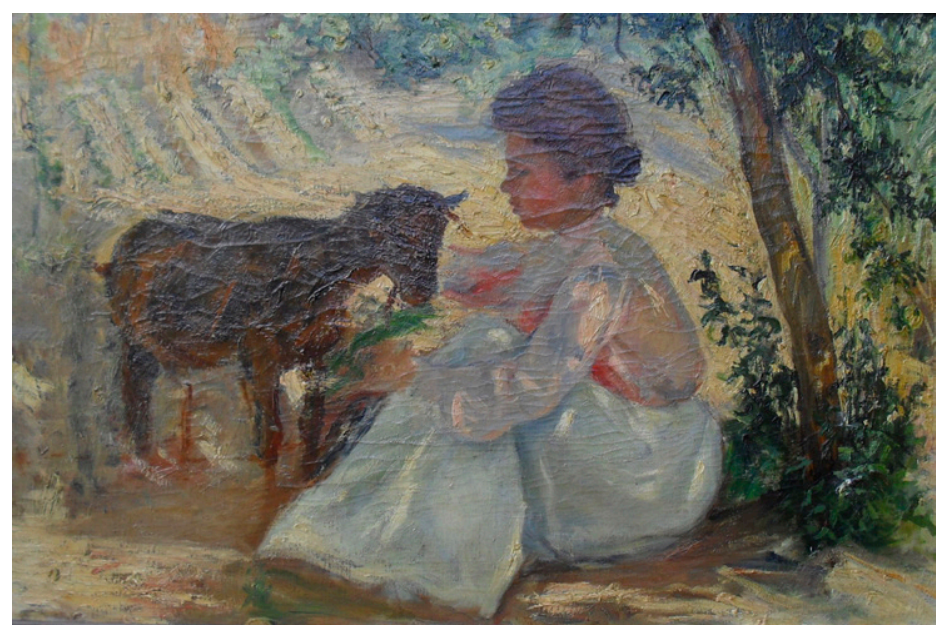

Fig. 5. Aurelia Navarro, Niña con cabrita, s.f. Óleo sobre lienzo, 43 × 67 cm. Colección Ignacio Navarro. abandonan el pesimismo anterior y muestran un carácter alegre, acorde con los episodios anecdóticos y joviales que se recrean. Algunas de estas jóvenes son descritas con las vestimentas populares andaluzas, trajes de volantes y mantones con flecos, que tan buena acogida tenían en el mercado nacional e internacional. Es el caso de Joven con mantón y abanico ${ }^{48}$ (Fig. 1) obra que Aurelia Navarro ejecuta al carbón, aunque incluyendo al pastel los brillantes colores del abanico, de la flor en el cabello y de la falda de volantes; en ella se advierte que el riguroso sentido del dibujo que posee la artista adopta un carácter fluido y ondulado, concediendo dinamismo a la representación; asimismo, es reseñable la magistral captación del gesto espontáneo de la modelo, con una expresión risueña y sincera.

En otras escenas costumbristas de este mismo momento, la artista sitúa a sus protagonistas en espacios al aire libre, lo que le permite explorar y describir el impacto de las luces y de las sombras. Son, en este sentido, numerosas las composiciones protagonizadas por mujeres en jardines y patios granadinos, dispuestas bajo los naranjos cuyas hojas tamizan de forma caprichosa la luz que se refleja sobre la figura, mientras el paisaje, al fondo, se desdibuja bajo la cegadora luz del estío granadino. En algunas ocasiones, las protagonistas son campesinas que aparecen acompañadas por pavos y gallinas, mientras en otras ocasiones son los animales los protagonistas exclusivos de las obras, permitiéndose la artista mayores transgresiones en el uso de acusados empastes y una ejecución más sumaria. Resulta interesante comparar las pinturas que Aurelia Navarro y su maestro, Tomás Muñoz Lucena, ejecutaron sobre los mismos motivos, ya que, además de testimoniar los intereses comunes de ambos pintores, evidencian la personalidad creativa propia de la artista. Así, el motivo de la joven pavera fue representado por los dos artistas en 1903, en obras que describen a la misma modelo rodeada por un paisaje rural y acompañada por un grupo de pavos. Muñoz Lucena realizó dos obras sobre esta pavera, un óleo y una aguada para la revista La Ilustración Española, mostrando a la modelo sentada, en una composición equilibrada y estática. Por su parte, Aurelia Navarro prefirió una composición más dinámica, describiendo a la pavera de pie, andando con cierta soltura, lo que provoca el movimiento ondulado de sus ropas, y colocando la vara sobre sus hombros en una actitud naturalista y espontánea; el punto de vista en contrapicado utilizado por la artista hace que la figura destaque sobre un amplio celaje blanco, otorgando un carácter de modernidad a la composición. En este tipo de obras protagonizadas por jóvenes con animales situadas en entornos naturales se 


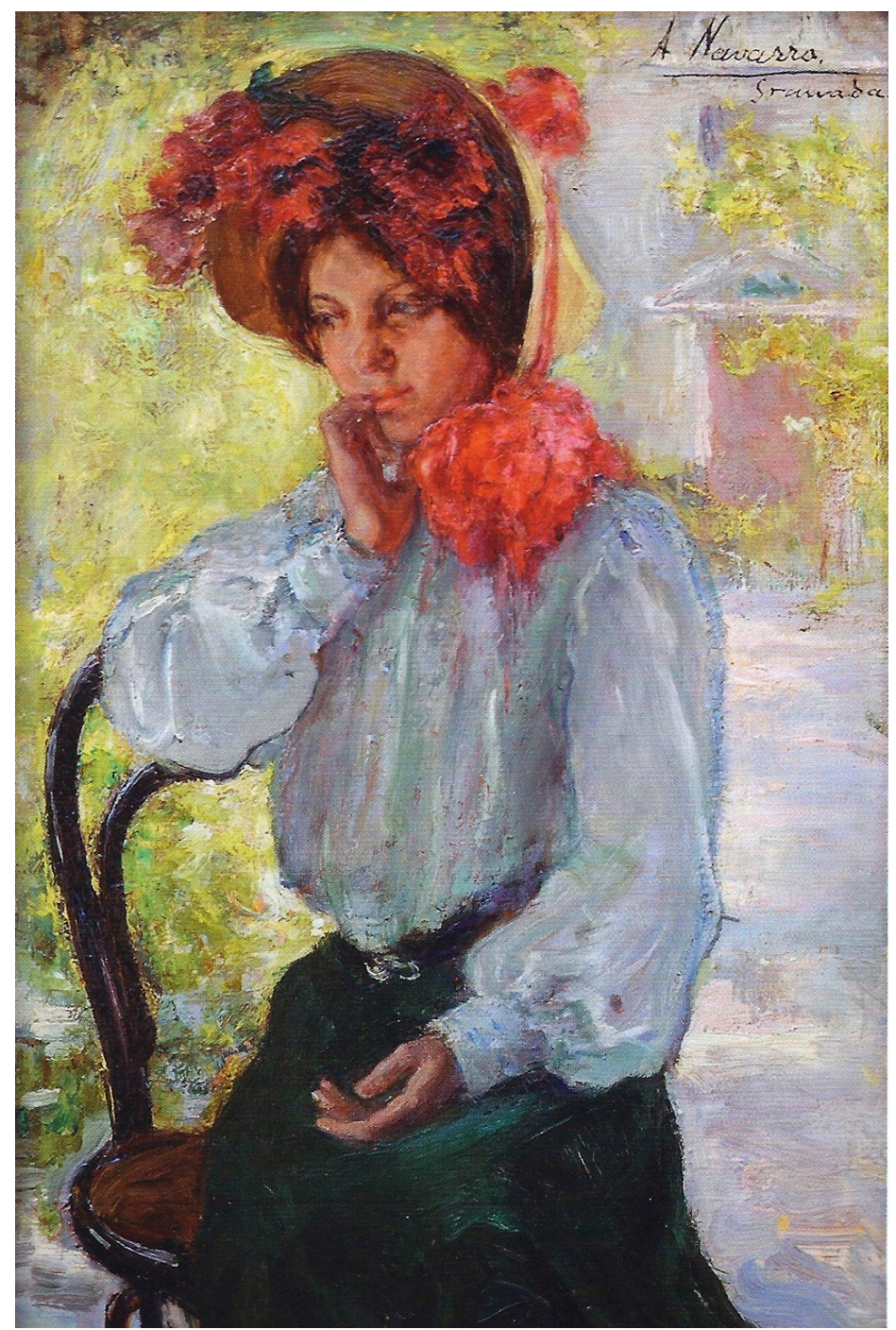

Fig. 6. Aurelia Navarro, Pensativa, s.f. Óleo sobre lienzo, $35 \times 21$ cm. Colección Casa Ajsaris, Granada. encuadra la pintura Niña con cabrita ${ }^{49}$ (Fig. 5) un estudio en el que Aurelia Navarro experimenta con soluciones muy esenciales en la configuración de los volúmenes, trazados con pinceladas anchas y empastadas, y, sobre todo, con la captación de los contrastes lumínicos.

Ese espíritu innovador que Aurelia Navarro muestra en el tratamiento de las gamas cromáticas y en la aplicación de una pasta pictórica con empastes matéricos, muy ricos en texturas, se advierte en la pintura Pensativa ${ }^{50}$ (Fig. 6), perteneciente a la colección Casa Ajsaris. La protagonista de la obra es una joven que, sentada en un espacio ajardinado, se encuentra ajena a todo lo que la rodea y absorta en sus pensamientos. A su alrededor, la artista ha recreado un entorno inundado de luces rosas y doradas que resplandecen, sobre todo, en el brillante verdor de la vegetación, dispuesto en arriesgado contraste con el bermellón de las flores prendidas en el sombrero. Predominan en la composición las reverberaciones lumínicas que crean interesantes juegos cromáticos especulares, como se aprecia, especialmente, en la blusa de la modelo.

\section{"Una artista que vale y que puede estar por derecho propio"} El estudio de la trayectoria creativa de Aurelia Navarro y el análisis de la recepción de su producción por parte de la crítica de arte obliga a una reflexión, que excedería el límite de páginas de este trabajo, sobre la presencia y la valoración de las artistas en la escena cultural española de comienzos del siglo XX.

Las palabras que inician este apartado, que fueron dirigidas a la artista en El Defensor de Granada en 1908, son representativas de la opinión favorable y, más importante aún, del tratamiento respetuoso y alejado de los habituales enfoques sexistas que la artista obtuvo, de forma generalizada, por parte de los

\footnotetext{
49. La pintura, óleo sobre lienzo $(43 \times 67 \mathrm{~cm})$, pertenece a la colección Ignacio Navarro.

50. La obra, óleo sobre lienzo $(35 \times 21 \mathrm{~cm})$ está firmada "A. Navarro/ Granada." Sobre la pintura, cfr. el catálogo de la exposición Granada artística en Casa Ajsaris; Segura Bueno, Granada artística en Casa Ajsaris, 228. Mi agradecimiento a los propietarios de la obra, D. Juan Manuel Segura Bueno y D. Francisco Jiménez Rodríguez, por haber permitido su reproducción en esta publicación.
} 
críticos y ello, a pesar de ser mujer. Resulta, en este sentido, sorprendente que incluso cuando optó por traspasar la frontera de lo considerado apropiado para las mujeres artistas, como era el caso de la mencionada pintura Desnudo de mujer, presentada en la Exposición Nacional de Bellas Artes de 1908, la mayoría de los críticos se afanaran en defender y en justificar dicha obra, refutando los hueros argumentos moralistas que, no obstante, continuaban estando vigentes en ese momento. Se reviste, igualmente, de un carácter ciertamente excepcional el hecho de que la artista fuera comparada, de forma persistente, con sus colegas varones granadinos, así como que fuera incluida en el selecto grupo de artistas consagrados de la ciudad, sin que su condición de mujer lo obstaculizara, ni se viera reflejada en las valoraciones de los críticos.

Son cuestiones sobre las que resulta necesario continuar investigando, no solo para conocer con profundidad la interesante personalidad creativa de Aurelia Navarro, sino para alcanzar un mejor y más completo conocimiento de las artistas españolas en las primeras décadas del siglo XX y, con ello, un mejor y más completo conocimiento de la historia del arte en Espańa a comienzos de dicha centuria.

\section{Referencias}

\section{Fuentes bibliográficas}

Aranda Bernal, Ana. "Ser mujer y artista en la España de la Edad Moderna." En Roldana, coordinado por Antonio Torrejón y José Luis Romero, 33-51. Sevilla: Consejería de Cultura, Junta de Andalucía, 2007.

Diego, Estrella de. La mujer y la pintura del XIX español (Cuatrocientas olvidadas y algunas más). Madrid: Ed. Cátedra, 1987.

Illán Martín, Magdalena. “Aurelia Navarro.” En Pintoras en España (1859-1926). De María Luisa de la Riva a Maruja Mallo, coordinado por Magdalena Illán Martín y Concha Lomba Serrano, 158. Zaragoza: Prensas de la Universidad de Zaragoza, 2014.

Illán Martín, Magdalena, y Custodio Velasco Mesa. “Un verdadero pintor’: María Luisa Puiggener en la escena artística sevillana de comienzos del siglo XX," Laboratorio de Arte, no. 30 (2018): 401-18.

Lomba Serrano, Concha. Bajo el eclipse. Pintoras en España (1880-1939). Madrid: CSIC, 2019.

Museo Virtual Diputación de Granada. “Aurelia Navarro Moreno.” Consultado el 30 de enero de 2019. http://museovirtual.dipgra.es/es/artista/aurelia-navarro-moreno

Parada y Santín, José. Las pintoras españolas. Boceto histórico-biográfico y artístico. Madrid: Imprenta del Asilo de Huérfanos del S. C. de Jesús, 1902.

Rodrigo Villena, Rocío. "La galantería: una forma de sexismo en la crítica del arte femenino en España (1900-1936).” Asparkía, no. 31 (2017): 147-66.

Rodríguez Titos, Juan. Mujeres de Granada. Granada: Diputación Provincial de Granada, 1998.

Segura Bueno, Juan Manuel. Granada artística en Casa Ajsaris. Granada: Asociación Granada artística, 2017.

Tomás Muñoz Lucena. Un cordobés en Granada. Granada: Asociación Granada artística, 2018.

Valverde, Mercedes y Francisco Zueras. Un siglo de pintura cordobesa, 1791-1891. Córdoba: Diputación Provincial de Córdoba, 1984.

\section{Fuentes periodísticas}

$A B C, 11$ de junio de 1908.

Baires, Carlos. “Deberes de la mujer." Álbum del Salón, 1904. 
Balsa de la Vega, Rafael. "Exposición General de Bellas Artes II. La pintura.” La Ilustración española y americana, 15 de mayo de 1908.

Caparrós, José María. “Exposición de Otoño.” Noticiero granadino, Granada, 29 de septiembre de 1908.

Casanova, Santiago. "Los artistas andaluces en la Exposición de Bellas Artes." La Alhambra, Granada, 30 de mayo de 1906.

Castillo, Aureliano del. "La exposición del Centro." El Defensor de Granada, 1 de octubre de 1908.

"Centro artístico." El Defensor de Granada, 1 de julio de 1916.

"Centro Artístico y Literario. Exposición de Otoño. Sala III." Gaceta del Sur, 6 de octubre de 1908.

El Álbum ibero americano, no. 23, 22 de junio de 1904.

El Defensor de Granada, 1 de marzo de 1904.

El Defensor de Granada, 1 de junio de 1904.

El Defensor de Granada, 9 de septiembre de 1906.

El Defensor de Granada, 29 de mayo de 1908.

"En la provincia." El Defensor de Granada, 5 de febrero de 1898.

"En la provincia." El Defensor de Granada, 15 de marzo de 1898.

“Exposición de Bellas Artes. Elogio del bello sexo.” El País, 8 de mayo de 1908.

"Exposición del Centro Artístico y Literario." La Alhambra, 15 de julio de 1908.

"Exposición del Centro Artístico y Literario." La Publicidad, 18 de junio de 1908.

Gaceta de la Asociación de Pintores y Escultores, no. 3, septiembre de 1910.

La Alhambra, Granada, 15 de enero de 1908.

La Alhambra, Granada, 15 de mayo de 1908.

La Alhambra, Granada, 31 de mayo de 1908.

La Alhambra, Granada, 30 de junio de 1914.

"La Asociación de Pintores y Escultores." Gaceta de la Asociación de Pintores y Escultores, no. 1, julio de 1910.

"La exposición de labores." El Defensor de Granada, 8 de septiembre de 1906.

"La exposición del Centro." El Defensor de Granada, 27 de septiembre de 1908.

"La exposición del Centro". El Defensor de Granada, 10 de junio de 1914.

La Publicidad, 14 de mayo de 1908.

Martínez de Federico, José. "La exposición de Bellas Artes." La Publicidad, 30 de junio de 1908.

Noticiero granadino, 31 de mayo de 1904.

"Tercera medalla por un Retrato." Noticiero granadino, 26 de mayo de 1906.

"Un cuadro hermoso." La Publicidad, 6 de octubre de 1908.

“Una artista de mérito." El Defensor de Granada, 14 de mayo de 1908.

Valladar, Francisco de Paula. "Los pintores granadinos en la Exposición Nacional." El Defensor de Granada, 24 de mayo de 1908.

---. "Los pintores granadinos en la Exposición Nacional II.” El Defensor de Granada, 29 de mayo de 1908.

---. "Los pintores granadinos." La Alhambra, 31 de mayo de 1908.

---. "Exposición del Centro artístico y literario. Expo caricaturas y tarjetas postales." La Alhambra, 15 de julio de 1908.

Fecha de recepción: 07/06/2018

Fecha de revisión: 13/06/2018

Fecha de aceptación: 05/11/2018 